\title{
Preoperative medical consultations: impact on perioperative management and surgical outcome
}

\author{
[Consultations médicales préopératoires : conséquence sur la prise en charge péri- \\ opératoire et les suites opératoires]
}

Robert I. Katz MD, Linda Cimino MS RN CPNP ANP, Stephen A. Vitkun MD MBA PhD

Purpose: This study was designed to assess the effect of preoperative medical consults on both perioperative management and surgical outcome.

Methods: The charts of 387 consecutive patients over the age of 50 undergoing non-cardiac, elective surgery during a six-week period were retrospectively examined. Patient factors including age, ASA status, gender, type of surgery, outcome (death, unexpected intensive care unit admission or uncomplicated discharge), presence of medical consult, and, in those cases where a medical consult was present, stated reason for the consult, the ordering physician, and recommendations of the consultant, were recorded.

Results: 138 patients receiving medical consults (35.7\%) were identified (a total of I 46 consults). The most common stated purpose of the consults examined was "preoperative evaluation." In only five consults (3.4\%) did the consultant identify a new finding. Sixty-two consults (42.5\%) contained no recommendations. There was no statistically significant difference in outcome between those patients who received a medical consult and those who did not.

Conclusion: A review of I 46 medical consults suggests that the majority of such consults give little advice that truly impacts either perioperative management or outcome of surgery.

Objectif : Évaluer l'effet des consultations médicales préopératoires sur la prise en charge périopératoire et les suites opératoires.

Méthode : Nous avons procédé à l'examen rétrospectif des dossiers de 387 patients consécutifs de plus de 50 ans qui, au cours de six semaines, ont été admis pour une intervention chirurgicale réglée non cardiaque. Nous avons noté l'âge, l'état physique ASA, le type d'intervention chirurgicale, les suites (décès, admission imprévue à l'unité des soins intensifs ou absence de complications), la présence de con- sultation médicale et la raison de la consultation, le médecin référant et les recommandations du consultant.

Résultats : Nous avons trouvé 138 patients (35,7\%) vus en consultation médicale pour un total de 146 consultations. Le motif de consultation le plus courant était «l'évaluation préopératoire». Dans cinq cas seulement (3,4\%) le consultant a découvert un nouveau problème. Soixante-deux consultations (42,5\%) ne contenaient aucune recommandation. Les suites opératoires n'étaient pas statistiquement différentes entre les patients vus ou non en consultation médicale.

Conclusion : Une revue de 146 consultations médicales montre que la majorité donne peu d'avis à incidence véritable sur la prise en charge périopératoire ou sur les suites postopératoires.

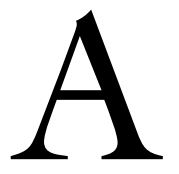

NESTHESIOLOGISTS and surgeons frequently request preoperative consultation from internists and family practitioners for patients with pre-existing or suspected disease. There can be considerable confusion, however, amongst physicians regarding both the reasons for which a consult was requested ${ }^{1}$ and the ultimate purposes that the consult serves. ${ }^{2}$ Such confusion often results in consultants' recommendations being ignored. ${ }^{3}$ Kleinmann found that very few anesthesiologists or surgeons specify what is being requested when asking for a cardiology consult. ${ }^{4}$ Lee $^{1}$ documented that in $14 \%$ of cases, requesting physicians and medical consultants actually disagreed on the reasons for the consult. Rudd, ${ }^{5}$ in a study on preoperative

From the Department of Anesthesiology, State University of New York at Stony Brook, Stony Brook, New York, USA.

Address correspondence to: Dr. Robert I. Katz, Department of Anesthesiology, S.U.N.Y. at Stony Brook, Stony Brook, N.Y. 11794 , USA. Phone: 631-444-2975; Fax: 631-444-2907; E-mail: rikatz@aol.com

Funding Source: Department of Anesthesiology, SUNY Stony Brook.

Disclaimer: Portions of this article have been presented at the American Society of Anesthesiologists Annual Conference, Dallas, October, 1999.

Accepted for publication December 28, 2004.

Revision accepted April 5, 2005. 
medical consultations for diabetic patients, found that no specific question was asked by the requesting physician in $24 \%$ of cases, and in $12 \%$, consulting physicians ignored the questions that were asked.

There have been several studies regarding the functional utility of cardiology consults to the preoperative process, ${ }^{2,6}$ as well as papers describing the format of the consult itself. ${ }^{7,8}$ In 1998, we examined the expectations and intentions of the anesthesiologists and surgeons who request cardiology consults, as well as those of the cardiologists who perform them. ${ }^{9}$ We documented that there is often disagreement amongst the specialties as to the reasons for such consults being obtained. We also documented that cardiology consults are rarely useful, either because they serve no accepted purpose, make no recommendations, or because the recommendations made are routine. The purpose of the current study was to determine what impact medical consults - including but not limited to cardiology consults - have on both perioperative management and surgical outcome.

\section{Materials and methods \\ Chart review}

With approval of the Institutional Committee on Research Involving Human Subjects (CORIHS), 422 consecutive patients over the age of 50 undergoing elective non-cardiac surgery during the months of January-February 1998, were identified and their medical records requested. Medical records were retrospectively examined and all patients having medical consults were identified. A medical consult was defined as a note in the chart from an internist or family practitioner, other than the admitting history and physical, dated within 30 days of scheduled surgery. In addition, if the chart made a mention of a "verbal consult," having been obtained, it was counted toward the total number of consults identified. In such a case, the patient data was included for demographic purposes, but no other conclusions were drawn regarding the consult itself.

Medical consults were reviewed by the authors for diagnoses, recommendations, stated reason for the consult, and specialty of the requesting physician. For the sake of analysis, "proceed with surgery," was regarded as a recommendation, since this phrase contains an active verb, while "cleared for surgery," was considered a statement, not a recommendation, since it urges no action upon the recipient. The medical records were examined to determine the effect of such recommendations on perioperative management, as well as outcome of surgery-specified as death, unexpected admission to the intensive care unit (ICU) or
TABLE I Demographics

\begin{tabular}{llll}
\hline & Medical consult & No consult & P value \\
\hline Gender & & & $P<0.05$ \\
Male $(n=184)$ & 75 & 109 & \\
Female $(n=203)$ & 63 & 140 & \\
Age $(\mathrm{yr}),(P<0.0001)$ & $n=138$ & $n=249$ & $P<0.0001$ \\
& $67.8 \pm 10.1$ & $63.1 \pm 9.9$ & \\
ASA status & $n=138$ & $n=244$ & $P<0.0001$ \\
ASA I & 2 & 15 & \\
ASA II & 48 & 126 & \\
ASA III & 86 & 91 & \\
ASA IV & 2 & 12 & \\
Outcome & $n=138$ & $n=249$ & $P=0.90$ \\
Routine discharge & 136 & 245 & \\
Unexpected intensive & 2 & 4 & \\
care unit admission & & & \\
/death & & & \\
Type of surgery & $(n=138)$ & $(n=249)$ & $P=0.0001$ \\
Thoracic & 2 & 8 & \\
Ear/nose/throat & 13 & 12 & \\
General & 18 & 68 & \\
Gynecological & 11 & 31 & \\
Neurological & 4 & 11 & \\
Ophthalmologic & 11 & 36 & \\
Dental & 1 & 1 & \\
Orthopedic & 25 & 32 & \\
Plastics & 3 & 27 & \\
Urological & 38 & 15 & \\
Vascular & 12 & & \\
\hline
\end{tabular}

otherwise uncomplicated discharge. Unexpected admissions to the ICU were defined as those admissions for which a preoperative request for an ICU bed had not - as is our approved institutional procedure been made.

\section{Statistical analysis}

Continuous data (mean \pm standard deviation, where appropriate), were analyzed by Student's t test. Categorical data, including surgical outcome, were analyzed by Chi-square. Data analysis utilized Statview software (SAS Institute, Berkeley, CA, USA). In all cases, $P<0.05$ was considered to be statistically significant.

\section{Results}

The medical records of 422 consecutive patients over the age of 50 scheduled for elective, non-cardiac surgery were requested. After three requests, 387 medical records were found (91.7\%). Upon review of these records, 138 patients having medical consults (35.7\%) were identified. A number of patients had more than one consult in the chart, for a total of 146 
TABLE II Concordance with recommendations

\begin{tabular}{|c|c|c|c|c|}
\hline Preoperative recommendations & Total & Yes & No & Uncertain \\
\hline Regarding medications & 80 & 56 & 5 & 19 \\
\hline Regarding testing (laboraties, etc.) & 15 & 13 & 0 & 2 \\
\hline $\begin{array}{l}\text { Regarding lifestyle changes } \\
\text { (stop smoking, decrease ETOH, etc) }\end{array}$ & 6 & 3 & 0 & 3 \\
\hline $\begin{array}{l}\text { Regarding further action } \\
\text { (NPO, involve cardiology, etc.) }\end{array}$ & 5 & 5 & 0 & 0 \\
\hline Preoperative percentage & & 72.6 & 4.7 & 22.6 \\
\hline Intraoperative recommendations & Total & Yes & No & Uncertain \\
\hline Regarding medications & 14 & 7 & 7 & 0 \\
\hline Regarding monitoring & 24 & 24 & 0 & 0 \\
\hline $\begin{array}{l}\text { Regarding procedures } \\
\text { (type of anesthesia, etc.) }\end{array}$ & 6 & 4 & 1 & 1 \\
\hline Intraoperative percentage & & 79.6 & 18.2 & 2.3 \\
\hline Postperative recommendations & Total & Yes & No & Uncertain \\
\hline Regarding medications & 2 & 1 & 0 & 1 \\
\hline Regarding monitoring & 2 & 1 & 0 & 1 \\
\hline $\begin{array}{l}\text { Regarding procedures } \\
\text { (hydrate, TED stockings, etc.) }\end{array}$ & 10 & 6 & 0 & 4 \\
\hline Regarding testing (laboratories, etc.) & 14 & 9 & 3 & 2 \\
\hline Posperative total & 28 & 17 & 3 & 8 \\
\hline Postoperative percentage & & 60.7 & 60.7 & 28.6 \\
\hline Totals & 178 & 129 & 16 & 33 \\
\hline Percent totals & $100 \%$ & $72.3 \%$ & $9.0 \%$ & $18.5 \%$ \\
\hline
\end{tabular}

medical consults. Patient demographics, types of surgery and specific surgeries for patients receiving medical consults are listed in Table I. There were differences between patients who received consults and those who did not according to age $(P<0.0001)$, ASA status $(P<0.0001)$, type of surgery $(P=0.0001)$ and gender $(P<0.05)$. There were no differences in outcome between groups $(P=0.9046)$.

Sixty-seven consults were identified as having been ordered by surgeons $(45.9 \%)$. Five were ordered by other internists or family practitioners $(3.4 \%)$. It could not be determined who ordered the remaining 74 consults $(50.7 \%)$. Twenty-eight consults (19.2\%) were ordered for "clearance." Twenty (13.7\%) were ordered for "evaluation." Two simply stated "consult" or "consult preoperatively." One consult asked for a "risk assessment" and one consult requested a "re-assessment." A specific reason for obtaining the consult could not be determined for the remaining 94 (64.4\%).

Sixty-two consults $(42.5 \%)$ made no recommendations. Forty-nine consults (33.6\%) "cleared" the patient. Twenty-nine consults $(19.9 \%)$ gave a risk assessment, in all cases a simple statement such as "minimal increased risk" or "no increased risk." No consult attempted to quantify such risk. One hundred twenty-one consults (82.9\%) listed the patients' diag- noses. Five consults identified a finding not previously mentioned in the admitting history and physical exam: two patients with rales, one patient with an "abnormal blood glucose," one patient with new onset pretibial edema and one patient with new occlusion of a prior right coronary artery bypass graft. The consultant added lasix and potassium chloride to the medical regimen of the patient with pretibial edema, and for the patient with occlusion of coronary artery bypass graft, the consultant prescribed metoprolol, isosorbide and simvastatin. Four consults (2.7\%) attempted to dictate the type of anesthesia (specifying either local or regional anesthesia).

Recommendations and concordance with such recommendations are summarized in Table II. A total of 178 recommendations were made by the consultants. A reading of the medical records could determine that $129(72.5 \%)$ were followed. Sixteen recommendations $(9.0 \%)$ were not followed, and it could not be determined if the remaining 33 recommendations (18.5\%) were followed.

\section{Discussion}

In 1998, we surveyed 400 surgeons, 400 cardiologists and 400 anesthesiologists regarding the intended purposes and perceived utility of preoperative cardiology 
consults. ${ }^{9}$ A majority of all three specialties felt that diagnosis and treatment of medical conditions, providing work-up data for the anesthesiologist to use in formulating a treatment plan and "medical-legal obligations" were all valid reasons for requesting a consult. Surgeons and cardiologists (but not anesthesiologists) tended to believe that "clearing" a patient, suggesting intraoperative monitoring and advising as to the safest type of anesthesia were valid reasons for requesting a consult. Our survey also demonstrated that there was no generally accepted definition for the term "cleared for surgery." A majority of all three groups felt that the best definition of the term was: "the patient's condition is medically optimized." However, $36 \%$ of the cardiologists felt that the best definition was: "the risks of proceeding are outweighed by the benefits," and $22 \%$ of the surgeons felt that the best definition was: "you are permitted to proceed with the case." Despite such confusion, the term is still commonly used.

In 1983 , a study by Lee $^{1}$ documented that in $14 \%$ of cases, requesting physicians and medical consultants actually disagreed on the reasons for the consult. Rudd, ${ }^{5}$ in a study on preoperative medical consultations for diabetic patients, found that no specific question was asked by the requesting physician in $24 \%$ of cases, and in $12 \%$, consulting physicians ignored the questions that were asked.

In our institution, any physician involved in a patient's care may recommend a consult. This recommendation is routinely referred to the admitting physician, which may be an internist, family practitioner, or in the case of patients scheduled for surgery, most commonly a surgeon. It is the responsibility of the admitting physician to actually request the consult. Hospital protocol states that a written consult request specifying a reason for the consult is to be sent to the consultant by the requesting physician. In our current review, however, the majority of charts contained no written consult request. Granting the possibility that verbal communication took place between the requesting and consulting physicians, neither the reasons for the consult request, nor the requesting physician, could be determined from these charts. It is of course possible that some of the notes regarded as "consults" may not have been requested at all. We have no way of determining whether or not an internist or family practitioner, knowing that his patient was scheduled for surgery, might have decided to send in an unsolicited report. Nevertheless, our data support the conclusion that such reports have little discernible impact upon management.

The group having consults did not differ in outcome from the group not receiving consults, but did differ in several demographic respects, making it difficult to ascribe this finding to the presence or absence of a consult. In addition, of course, there are other outcomes than routine discharge, death and unexpected ICU admission that we could have examined (e.g., wound infection, deep venous thrombosis and length of stay). We decided not to do so because the retrospective nature of the study made it difficult to accurately gather such data, particularly since approximately $60 \%$ of the surgical procedures in our institution are done on an ambulatory basis. We think it reasonable to say, however, that consults which do not impact management cannot impact outcome.

In our previous survey, ${ }^{9} 80.2 \%$ of anesthesiologists viewed that a cardiology consult was most useful when ordered by an anesthesiologist. Though it is possible that some of the consults in our current study were requested by anesthesiologists (perhaps communicated to the surgeon rather than to the consultant), we could not clearly identify a single instance where this was so.

Prior studies have shown rates of non-compliance on the part of requesting physicians with consultants' recommendations ranging from $17 \%$ to $46 \%, 3,10-12$ rates confirmed by both our current and earlier study. These prior studies have all regarded the fact that the majority of consultants' recommendations are followed to be evidence that consults are useful to the surgeon and anesthesiologist. However, over $40 \%$ of the consults that we examined contained essentially no recommendations, and many of the recommendations given would seem to be either obvious or routine (e.g., keep glucose normal, monitor blood pressure, continue current medications, stop aspirin or coumadin prior to surgery) and would most likely have been instituted with or without a consultant's recommendation. We identified only two cases for which a new finding led a consultant to initiate changes in medications prior to surgery. Consultants recommended echocardiograms for three patients, for one of whom a stress test was also recommended. All four recommendations were carried out, which could possibly have resulted in delay of surgery. No evidence could be found, however, of these test results influencing either preoperative medication changes or intraoperative management. It is possible that some consultants made recommendations that resulted in case cancellation. Since we looked only at the charts of patients undergoing surgery, such data would not have been discovered by our methodology. We must also acknowledge that a retrospective chart review cannot always determine recommendations that may have been transmitted verbally, or the impact of such recommendations. 
Our data show a clear association between type of surgery and the likelihood of a medical consult. The reasons for this association are unclear, but may be partly explained by practice patterns, the age and the health of the patient. Patients of ASA status III and IV were more likely to receive a medical consult than patients of ASA status I or II, and increasing age is also positively correlated with medical consults (both, $P<$ 0.0001 ). Certainly, patients for urologic surgery tend to be elderly and many are in poor health, and at least one paper ${ }^{13}$ has documented that evaluation and preoperative optimization of vascular surgery patients is beneficial. It is surprising to us that only two out of 14 ASA status IV patients had medical consults. It may be that such patients are routinely under a physician's care and that their condition seemed to the surgeons and anesthesiologists involved in their case to be already optimized. Our finding that female patients are less likely than male patients to receive medical consults is also surprising, and we have no obvious explanation. However, a paper by Bell ${ }^{14}$ has documented that female patients are less likely than males to receive medically proven therapies for myocardial infarction. A study by Young et al. ${ }^{15}$ documents that women are less likely than men to receive appropriate work-up for sleep apnea. These authors speculate that health care workers might be more likely to disregard symptoms in women.

Bass et al., ${ }^{16}$ found that up to $80 \%$ of surgeons, anesthesiologists and consulting internists ordered laboratory testing that they themselves felt to be unnecessary in the belief that institutional rules, "medical-legal considerations" or one of the other specialties involved in the case would require them. Fischer, examining the costs and benefits of a preoperative anesthesia evaluation unit, ${ }^{17}$ showed that the number of laboratory tests and medical consults both decreased by greater than $50 \%$ when responsibility for surgical preparation of patients was given to the anesthesiology service alone. van Klei et al. ${ }^{18}$ found that a visit to a preoperative anesthesia evaluation unit by patients expected to be admitted after surgery resulted in a decrease in both cancelled cases and hospital length of stay. Our data suggest that many medical consults are requested for procedural reasons, not because specific medical questions need to be addressed but rather as a precautionary measure.

Our data were collected in 1998, and it is certainly reasonable to question whether changes in practice patterns and/or therapeutic options may have changed in the intervening time. However, our system of requesting and responding to consult requests has not changed in over 20 years, and there is no obvious reason to think that a review of current consults would yield different data.

Our chart review was confined to one institution and our results might differ from those that would be found at other institutions. However, our results are similar to those found on our prior study, examining cardiology consults alone, done at an academic medical centre more than 50 miles from our own. Furthermore, in both the prior and the current studies, many of the surgeons and consultants involved in our patients' care were in private practice. These physicians all have offices outside our hospital and are on the staff of at least one other hospital than our own. In addition, other studies than our own have found questionable impact on patient management by medical and cardiology consults ${ }^{4}$ as well as lack of specificity as to the reasons for requesting a consult ${ }^{4,5}$ and frequently poor communication between consultants and other physicians. ${ }^{1,5}$ It seems unlikely, therefore, that our results could be unique to any particular institution.

In the current study, well over $90 \%$ of consults were for patients undergoing surgery that a recent American College of Cardiology/American Heart Association report ${ }^{19}$ characterizes as "low" or "intermediate" risk. A considerable amount of time and resources are spent in performing such consults. Our data suggest that the majority of medical consults provide little advice which truly impacts either perioperative management or surgical outcome. A recent review $\operatorname{article}^{20}$ makes this same point, noting that the majority of cardiology consult requests are not at all specific, and that the consults therefore tend to make "broadly inclusive, general remarks about perioperative management..." Though the system outlined by Fischer ${ }^{17}$ whereby a single service orders all consults, has the advantages of both simplicity and efficiency, we do not think it inherently unreasonable to perpetuate a system whereby any physician involved in a patient's care has input into the process (our current system). We do, however, think it likely that the utility of medical consults under our current system would be greatly improved if a written request containing a clearly stated and generally accepted reason for the consult, were universal, and if consults were requested solely for patients whose disease processes were noted by the requesting physician to be potentially serious and either inadequately diagnosed or inadequately treated. We again note our earlier finding ${ }^{9}$ that the majority of anesthesiologists, surgeons and cardiologists regard "medical-legal considerations" to be a valid reason for requesting a consult. It seems likely to us that this attitude is at least partially responsible for 
the large number of consults that do not contribute to management. In the current era of cost cutting and managed care, resources for unnecessary consults are not likely to continue. Future studies are needed to assess costs associated with similar consults which do not address new problems and which do not influence medical management.

\section{References}

1 Lee T, Pappius EM, Goldman L. Impact of inter-physician communication on the effectiveness of medical consultations. Am J Med 1983; 74: 106-12.

2 Pupa LE Jr, Coventry JA, Hanley JF, Carpenter JL. Factors affecting compliance for general medicine consultations to non-internists. Am J Med 1986; 81 : 508-14.

3 Mackenzie TB, Popkin MK, Callies AL, Jorgensen CR, Cohn JN. The effectiveness of cardiology consultation. Concordance with diagnostic and drug recommendations. Chest 1981; 79: 16-22.

4 Kleinman B, Czinn E, Shah K, Sobotka PA, Rao TK. The value to the anesthesia-surgical care team of the preoperative cardiac consultation. J Cardiothorac Anesth 1989; 3: 682-7.

5 Rudd P, Siegler M, Byyny RL. Preoperative diabetic consultations: a plea for improved training. J Med Educ 1978; 53: 590-6.

6 Wells PH, Kaplan JA. Optimal management of patients with ischemic heart disease for noncardiac surgery by complementary anesthesiologist and cardiologist interaction. Am Heart J 1981; 102: 1029-37.

7 Moore RA, Kammerer WS, McGlynn TJ, Trautlein JJ, Burnside JW. Consultations in internal medicine: a training program resource. J Med Educ 1977; 52: 323-7.

8 Goldman L, Lee T, Rudd P. Ten commandments for effective consultations. Arch Intern Med 1983; 143: 1753-5.

9 Katz RI, Barnhart JM, Ho G, Hersch D, Dayan SS, Keehn L. A survey on the intended purposes and perceived utility of preoperative cardiology consultations. Anesth Analg 1998; 87: 830-6.

10 Ballard WP, Gold JP, Charlson ME. Compliance with the recommendations of medical consultants. J Gen Intern Med 1986; 1: 220-4.

11 Klein LE, Levine DM, Moore RD, Kirby SM. The preoperative consultation. Response to internists' recommendations. Arch Intern Med 1983; 143: 743-4.

12 Sears CL, Charlson ME. The effectiveness of a consultation. Compliance with initial recommendations. Am J Med 1983; 74: 870-6.

13 Fleisher LA, Eagle KA, Shaffer T, Anderson GF. Perioperative- and long-term mortality rates after major vascular surgery: the relationship to preoperative testing in the medicare population. Anesth Analg 1999; 89: 849-55.

14 Bell DM, Nappi J. Myocardial infarction in women: a critical appraisal of gender differences in outcomes. Pharmacotherapy 2000; 20: 1034-44.

15 Young T, Hutton R, Finn L, Badr S, Palta M. The gender bias in sleep apnea diagnosis. Are women missed because they have different symptoms? Arch Intern Med 1996; 156: 2445-51.

16 Bass EB, Steinberg EP, Luthra R, et al. Do ophthalmologists, anesthesiologists, and internists agree about preoperative testing in healthy patients undergoing cataract surgery? Arch Ophthalmol 1995; 113: 1248-56.

17 Fischer SP. Development and effectiveness of an anesthesia preoperative evaluation clinic in a teaching hospital. Anesthesiology 1996; 85: 196-206.

18 van Klei WA, Moons KG, Rutten CL, et al. The effect of outpatient preoperative evaluation of hospital inpatients on cancellation of surgery and length of hospital stay. Anesth Analg 2002; 94: 644-9.

19 Eagle KA, Berger PB, Calkins H, et al. ACC/AHA guideline update for perioperative cardiovascular evaluation for noncardiac surgery-executive summary. A report of the American College of Cardiology/ American Heart Association Task Force on Practice Guidelines (Committee to Update the 1996 Guidelines on Perioperative Cardiovascular Evaluation for Noncardiac Surgery). J Am Coll Cardiol 2002; 39: 542-53.

20 Park $K W$. Preoperative cardiology consultation. Anesthesiology 2003; 98: 754-62. 